FRACTURE PROCESSES AND FEACTURE TOUGHNESS IN POWDER FORGED STEELS

R. M. Pilliar, W. J. Bratina and R. A. Blackwe11*

INTRODUCTION

The concept of fracture mechanics has been applied to selected powder forged steels in an attempt to correlate fracture toughness, $\mathrm{K}_{\mathrm{IC}}$, with micro-structural and fracture characteristics of these materials. The second phase inclusions, either dispersed within the lattice or found at the prior powder particle boundaries, act as internal defects with associated stress concentration. Predominantly non-coherent, non-metallic inclusions are considered in this paper only, since they are expected to have a significant effect on fracture toughness. In some powder forged materials a few regions of bainite, fine pearlite and ferrite mixture were occasionally observed. These regions originated from iron-powder contamination as a result of powder processing practice; they do not, however, seem to have any effect on $\mathrm{K}_{\mathrm{Ic}}$ value [1]. This observation is in agreement with the Charpy V-notch impact test results [2].

The steels used in this investigation were low alloy $\mathrm{Cr}-\mathrm{Mn}$ and Ni-Mo steels, made by powder metallurgy techniques, subsequently hot forged to full density and then subjected to various heat treatments. The conventional notch impact test data have been shown to be of such low sensitivity as to make this method extremely unreliable in relating properties to structures. Therefore an evaluation on the basis of plane strain fracture toughness was made. Full density materials are required in order to obtain meaningful $K_{I c}$ values. At present, the fracture toughness test seems to be the most reliable test in assessing the integrity of powder forged parts subjected to stress applications.

\title{
MATERIALS AND PARAMETERS
}

The two types of low alloy steel compositions studied, i.e. Cr-Mn and Ni-Mo steel were the same as previously reported [3 - 7]. Cr-Mn steel contained approximately $1.5 \% \mathrm{Cr}, 0.8 \% \mathrm{Mn}$ and $0.33 \% \mathrm{C}$ whereas $\mathrm{Ni}-\mathrm{Mo}$ alloy contained $1.7 \% \mathrm{Ni}, 0.5 \% \mathrm{Mo}$ and $0.5 \% \mathrm{C}$. In same experiments, however, a Ni-Mo alloy steel with higher manganese $(0.42 \%)$ and lower nickel $(0.49 \%)$ content was used. A major effort to produce a high strength alloy powder steel has concentrated on these two alloy systems. It is known, that more stable oxide phases form in $\mathrm{Cr}-\mathrm{Mn}$ steels, whereas they are largely absent in Ni-Mo steels, because of the ease with wich they can be reduced. In higher manganese $(0.42 \%)$ Ni-Mo steels, however, larger numbers of oxide inclusions were observed after forging as compared with lower manganese $(0.20 \%) \mathrm{Ni}-\mathrm{Mo}$ steels [6]. Although these two types of steels were in this study, the conclusions relating the $K$ characteristics should be valid in general. The Cr-Mn type steel re-

*Ontario Research Foundation, Centre for Powder Metallurgy, Sheridan Park, Ontario, Canada, L5K $1 \mathrm{~B} 3$ 
presents the material, in which oxide inclusions play a dominant role in fracture; the interparticle, (i.e. along prior powder particle boundaries) tract of fracture is expected to prevail. The Ni-Mo type steel represents type of fracturich the fracture of the matrix, i.e. transparticle fracture, should be a common fracture feature.

As demonstrated before $[5,6]$ the total oxygen content in the form of As demonstrated is the most significant single contributing factor in various oxide $K_{\text {Ic }}$ value. The oxygen content was varied from 100 to $>1000 \mathrm{ppm}$, with the value of $300 \mathrm{ppm}$ taken arbitrarily as a line between 1000 ppontent.

The compact tension fracture toughness specimens were cut as shown in The compact the work in determining $\mathrm{K}_{\mathrm{Ic}}$ done previously was on Figure l. Most secimens with the notch perpendicular to the forging compact tensions and forging direction, orientation C, Figure 1. Only very recently plane and forging work on $K_{I c}$ anis has not been done yet. All tests were valid fracture on Cr-Mn stest toughness tests according tensile strength was in the order of $1600 \mathrm{MPa}$ B, were used.

NATURE OF INCLUSIONS AND FRACTURE SURFACE ANALYSIS IN Cr-Mn STEELS

rine The matrix produced from tempered martensite, after various thermo-mechanica forgings consisted of tenpered compressed during hot treatments. The oxidation cannot be forging into lens shapes of prevented during predominantly interparticle high stability of oxides in Cr-Mh stion powder particle fracture following the oxide inclusion path along prict surfaces, is expected to prevail in spere tegree of interparticle mixed with some transparticle fracture fracture is obviously expected in surfaces of specimens of either A substantially in spite of somewhat different orientation to crack arrester and crack divition, would, however, result in fracture $B$, easy crack propagation direction, wO A SEM fractograph of a specimen of surfaces parallel to the forge plane. A sigure 2 at low magnification $\mathrm{Cr}-\mathrm{Mn}$ steel in orientation $\mathrm{C}$ is shown in Figure $\mathrm{Cr}-\mathrm{Mn}$ steels, is observed (X160). The interparticle fracture, typture. The forging direction is with some regions of transparticle fracture. perpendicular to the apparent longitudinal partich magnification (X9400). particle fracture area is seen in Figure 3 at hurface of the original There is no question that the oxides on the surface later modified in powder particles have been broken during forging and later distribution is shape by solid state reactions. Their very fine, uniform dion. The in part responsible for the observed fine dimples. inclusions, approximately $1 \mathrm{\mu m}$ in diameter, are $\mathrm{x}$-ray techniques as oxide and were identified by electron diffraction spinels, and manganese-alumina-silicates. The transparticle, with the the matrix type fracture and has a coarse die average size of a dimple many times larger than the ated with these transinterparticle fracture zone. The inclusions associated particle dimples originate from
The energy required for fracturing the specimen, and subsequently the $\mathrm{K}_{\mathrm{Ic}}$ values can be assessed on the basis of dimple size. Transparticle fracture, characterized by the coarse dimpled structure, is associated with a larger amount of plastic work than the interparticle fracture shown in Figure 3, which consists of small, shallow dimples. Taken to the extreme, a further decrease in dimple size would lead to a featureless fracture surface approaching a cleavage type of fracture. Some isolated cleavage type not broken in the forging process.

The dimple size was introduced in the term, $\lambda_{c}$, in the equation: $\mathrm{K}_{\mathrm{Ic}} \approx \sqrt{2 \sigma_{\mathrm{y}} \mathrm{E} \lambda_{\mathrm{c}}}$ [8], where $\lambda_{\mathrm{c}}$ is interdimple spacing. The more general equation should include the plastically deformed zone area. From this relation the $K_{I c}$ value for transparticle fracture (1arger $\lambda_{c}$ ) is expected to be higher than for interparticle fracture (smaller $\lambda_{c}$ ). In practice, correlation of interdimple spacings to $K_{I c}$ is very difficult, although video tape was used and the total fracture surface was scanned. It should ide ecimen, Figure 2, and the actual value of $K_{I c}$ reflects the mixture of specture. An accurate estimate of an effective $\lambda_{c}$ is difficult.

NATURE OF INCLUSIONS AND FRACTURE SURFACE ANALYSIS IN Ni-Mo STEELS

The effect of higher manganese $(0.42 \%)$ content in some of the Ni-Mo steels The effect of higher manganese (0.42\% conter. A larger number of oxide used on oxide formation was reported earlower manganese $(0.20 \%)$ steel [6] inclusions was observed essentially of As in $\mathrm{Cr}-\mathrm{Mn}$ steels,

The fracture typical for $\mathrm{Cr}-\mathrm{Mn}$ steels, Figure 2, is not found in Ni-Mo The fracture typical for Cr-Mn steels, transparticle. The dimple network is seen in Figure 4 at X4200 magnification. Within some dimples inclusion the inclusions affecting properties in the low oxygen steel ind
are largely oxide phases.

The higher oxygen containing samples ( $>1000 \mathrm{ppm}$ ) also fractured in a typical re exposing the typical pattern of interparticle abent in Ni-Mo steels. The fracture was original particle morphology was a Figure 4), mixed with interparticle largely transparticle, (similac fracture was found to be affected by orientation. Orientation B, the easy crack propagation direction, was characterized by fracture surfaces associated with oxide inclusions lying in the plane of the fracture. These were sometimes relatively large. In Figure 5 such an area is shown at X1000 magnification. this size is atypical. However, its chemistry is typical for small clusions which are the product of fractured silicon, calcium, magnesium and particularly large inclusion is a complex silicon, calcium, magnesium an iron oxide. The detail of the same area at higher magnification (x20 Figure 6, revealed a large spherical inclusion and a great numer of smaller, somewhat irregular inclusions. The spherical inclusion was identified as containing manganese and silicon. Smaller, irregular inclusions are the fragments of large complex oxide particles and are 5 and 6 is perpendicular to the plane of the photograph. This area clearly 
shows the variety of shapes and compositions of inclusions, although the dimpled structure resembles strongly the fracture structure in Figure 4 , except for a large number of small inclusions within the dimples.

A fractograph of a sample with a fatigue precrack in orientation C, Figure 7, shows a large crack associated with oxide inclusions with small inclusion fragments within the dimples, (forging direction is perpendicular the field is remarkable and the dimpled $\mathrm{K}_{\text {Ic }}$ VALUES

A quantitative correlation of $\mathrm{K}_{\mathrm{Ic}}$ values with fracture processes as deduced from SEM fractographs is not possible at present. However, the qualitative correlation exists. As mentioned before, the total oxygen content largely in the form of various oxides is the most important factor in determining $K_{I c}$ values $[5,6]$. At $300 \mathrm{ppm}$ of oxygen, $\mathrm{K}_{\mathrm{Ic}}$ for $\mathrm{Cr}-\mathrm{Mn}$ steel was found to be in the range of $40 \mathrm{MPa} \cdot \mathrm{m} / 2$, and for Ni-Mo steel, $55 \mathrm{MPa} \cdot \mathrm{m}$. At lower oxygen level $(<100 \mathrm{ppm})$ the difference in $\mathrm{K}_{\mathrm{I}}$ for $\mathrm{Cr}-\mathrm{Mn}$ and $\mathrm{Ni}-\mathrm{Mo}$ steel should diminish; $\mathrm{K}_{\mathrm{Ic}}$ values of over $60 \mathrm{MPa} \cdot \mathrm{m} / 2$ were determined for both steels. The very recent data suggests that the difference in fracture toughness for $\mathrm{Cr}-\mathrm{Mn}$ and $\mathrm{Ni}-\mathrm{Mo}$ steels at the same oxygen level might not be very significant. An attempt was made to plot all avallable KIc data for the orientation $C$ test samples versus oxygen content and it appears that a single curve could be drawn regardless of steel composition ( $\mathrm{Cr}-\mathrm{Mn}$ versus $\mathrm{Ni}-\mathrm{Mo}$ ).

\section{ACKNOWLEDGEMENTS}

The authors are grateful to Mr. H. Paju for sample preparation and testing, to Messrs. P. O'Keefe and H. Lopers for metallographic examination, and to I. Murray and P. Richardson for assistance in scanning electron microscopy. This work was supported partially by a grant from the Federal Department of Industry, Trade and Commerce, Ottawa, Canada, as part of the Centre for Powder Metallurgy of the Ontario Research Foundation, and by the Ministry of Industry and Tourism, Province of Ontario.

\section{REFERENCES}

1. BRATINA, W. J., FOSSEN, W. F, HOLLINGBERY, D, R, and PILLIAR, R. M. Modern Developments in Powder Metallurgy, 9, MPIF, Princeton, N.J., 1977.

2. STEED, J. A., Powder Metallurgy, 18, 1975, 201

3. PILliar, R. M., BRATINA, W. J. and McGRATH, J. T., Modern Developments in Powder Metallurgy, 7, MPIF, Princeton, N.J., 1974, 51.

4. PILLIAR, R, M. LADANY $\bar{I}, T$ J MEYERS, G A. and WEATHERLY, G. C. Proc. Fourth Conf. on Powder Metallurgy, Vysoke-Tatry, Czechoslovakia, Part 1, 1974,233

๖. LADANYI, T. J., MEYERS, G. A., PIlliar, R. M. and WEATHERLY, G. C. Met. Trans. A, 6A, 1975, 2037.

6. PILLIAR, R. M., HOLLINGBERY, D. R. and FOSSEN, W. F., Int. J. of Powder Metallurgy and Powder Technology, (to be published).

. BRATINA, W. J. and GIBBON, W. M., Fourth European Symp. for Powder Metallurgy, Grenoble, France, 1975, paper 7-7-1.

8. HAHN, G. T. and ROSENF IELD, A. R., Met. Trans. A, 6A, 1975, 653.
FORGING DIRECTION

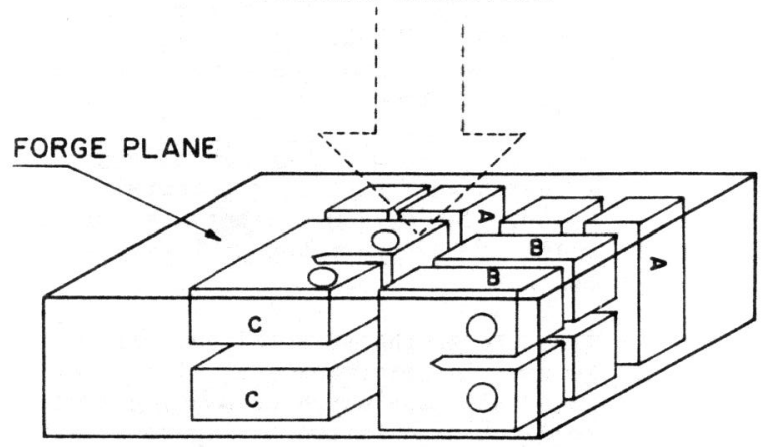

Figure 1 Schematic diagram showing three orientations of CT fracture toughness specimens

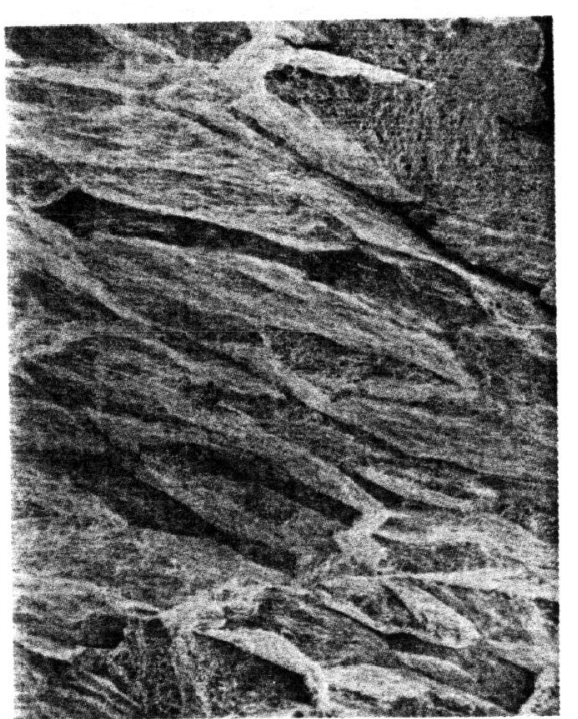

Figure 2 Fracture surface characteristic for Cr-Mn steel Interparticle fracture with a few areas of transparticle fracture is noted. X160 


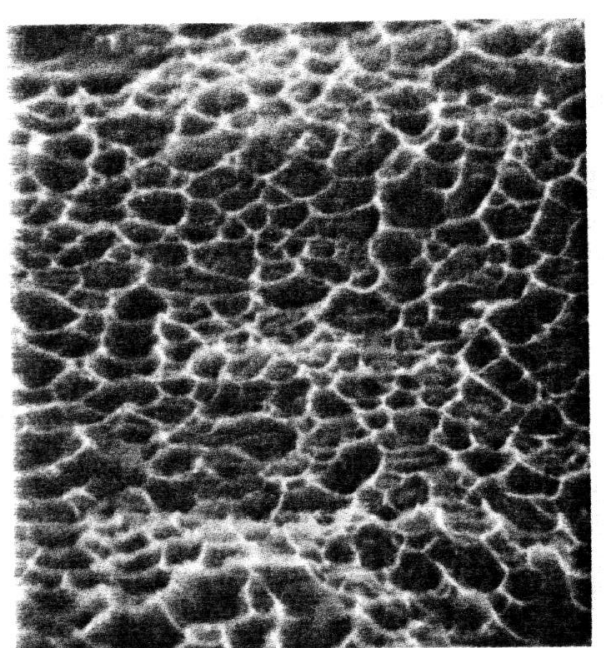

in $\mathrm{Cr}-\mathrm{Mn}$ steel. Structure timples, many associated with fine of small size dimples, many
inclusions, is seen.

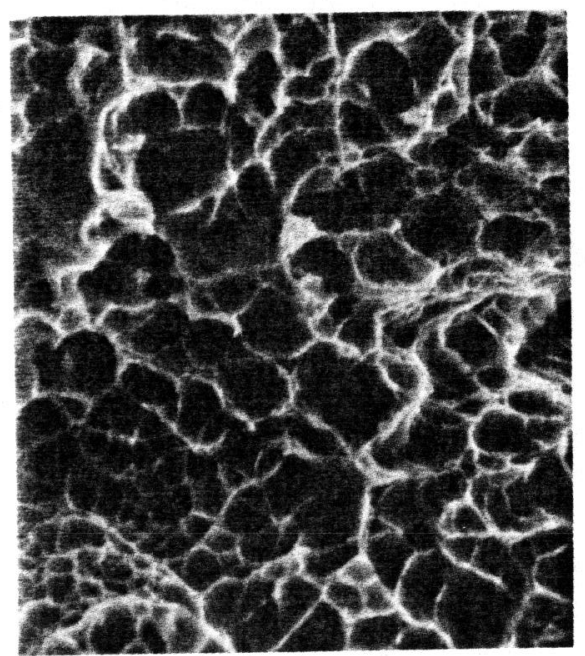

Figure 4 Transparticle fracture in Ni-Mo low oxygen steel. Note the dimple network with some inclusions. x4200

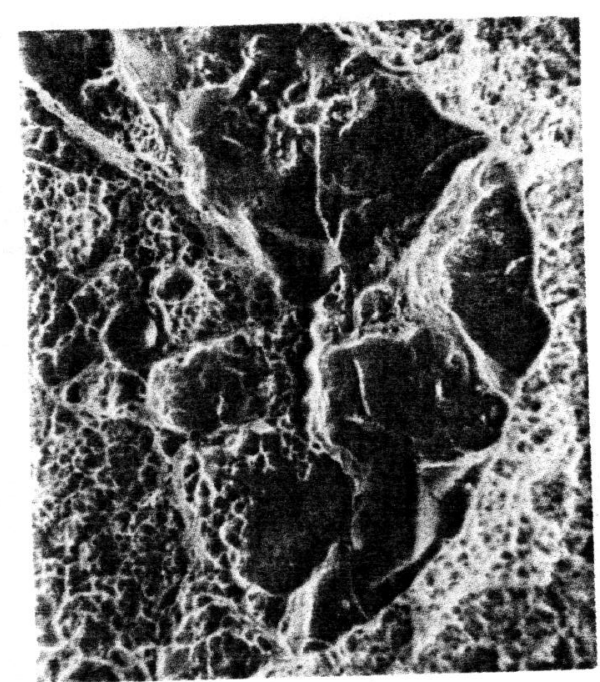

Figure 5 Fracture surface in Ni-Mo high oxygen steel with very large atypical inclusion. Orientation $B$. a ver plane of the photograph. X1000

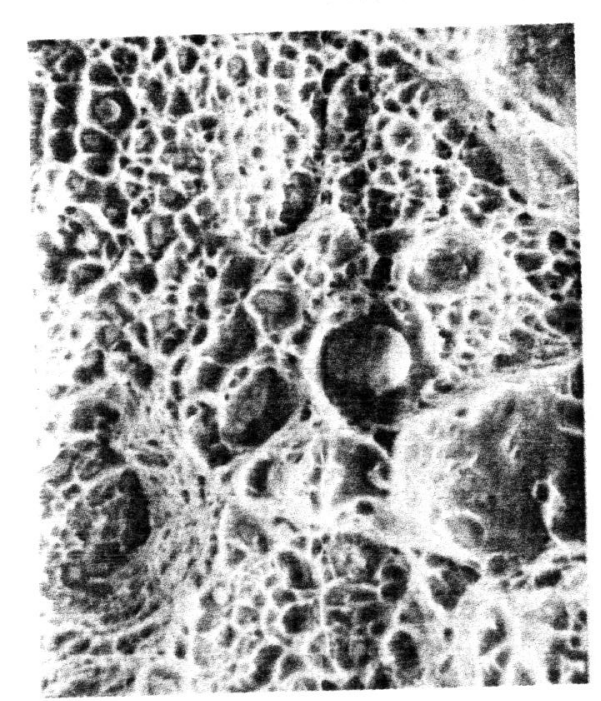

Figure 6 Detail of Figure 5. A large spherical inclusion and numerous oxide inclusions within the dimples are 2000 


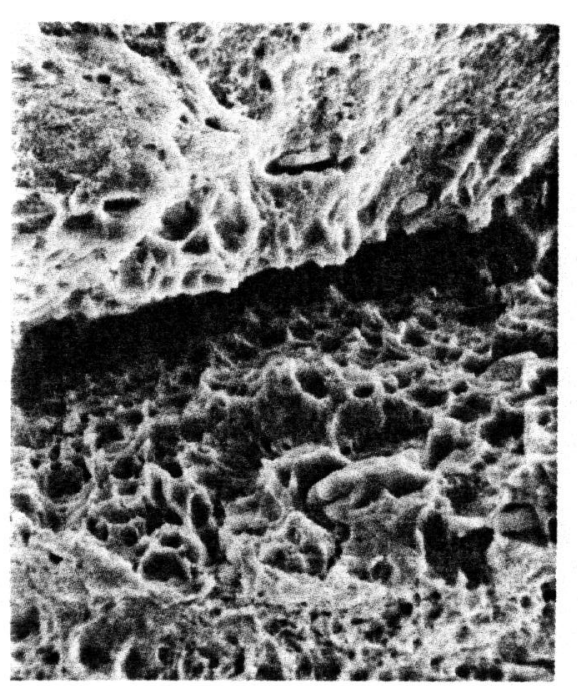

Figure 7 Fracture surface in Ni-Mo high oxygen steel with C. Forging direction is in the plane of the photograph and perpendicular to the large crack seen in the picture. X2000 